\title{
Literature Review on Examination Stress amongst School Going Students
}

\author{
Dr. Amitkumar Gosar, Saindhavi Venkatraman
}

\begin{abstract}
In today's rapidly growing world, people are completely occupied into their activities and have no time to think about their mental health. The fast growing era has led to the competitive edge amongst all the age groups and at the same time this as brought lot of stress in the life of each and every one. The magnitude of the stress might vary for an individual but since the stress bearing capacity also vary from person to person, the results of this stress are also varying in nature, leading to mental disorders like Anxiety and depression or a physiological disorders like high blood press, Diabetes or cardiac problem. The stress bearing capacity majorly depends on the personality type and traits of an individual and the school age is the major part of an individual's life in shaping the personality. Hence in this research article, the emphasis was given to check the literature, where the work has been published on examination stress of school going children.
\end{abstract}

Index Terms - Examination Stress, personality, intelligence, achievement motivation

\section{INTRODUCTION}

Stress of an examination is a particular type of stress which is felt by almost every person in life but the causes for such a feeling can be numerous under different situations and in different environments. The extent to feel such a stress can also vary from individual to individual. When students' aspirations are too high to reach but his abilities, interests, attitudes and capacities do not match with it, one may feel stress. An individual may excel in limited areas but sometimes when one wants to excel in every walk of life without considering one's own capabilities or under estimating own self may suffer from stress. When students do not plan their studies in the beginning of the academic year and don't set their aims of life, they may face difficulties before commencement of the examination, hence causing stress. Many students perceive examination as a threatening event. Their attitude towards examination is negative instead of working hard and developing confidence in them, they develop fear and remain tensed due to one or the other reason which may lead to stress during examination. Students learn more and more to achieve excellence. But

Dr. Amit Gosar, Department of Masters in Business Administration, Sikkim Manipal University, Navi Mumbai, India

Saindhavi Venkataraman, Department of Social studies, Indira Gandhi National Open University, Mumbai, India, when they don't meet their targets, they chose wrong methods of study like rote memorization etc. which lead them towards stress. The psychologists and educationists have been focusing their research proposals in the area of stress. They remained mostly in the fields of occupational stress, stressful life events and stress due to some chronic diseases etc. But less attention has been paid to the issue of examination stress realizing the present day need in the area of education where focus is upon mobilizing and directing the inner potentialities of students to cope with difficulties and achieve better. The variable of examination stress has been selected for investigation especially as it exists in relation to one's cognitive functioning. The other variables selected for the present study are personality, intelligence and achievement motivation. Students react differently with the event of examination. It is yet to be explored whether more intelligent students take the examination as challenge and utilise their maximum energy to do the best. Personality has different traits and any particular trait may help the individuals to react in a specific way for coming possibilities. Some students want to achieve the standard of excellence in every sphere of life but examination stress plays its role everywhere. It may vary with varying levels of personality, intelligence and achievement motivation. Hence, the investigator took the present study to account for the issue of examination stress.

\section{LiteratURE REVIEW:}

Review of literature is a vital part of any research. It helps the researcher to know the areas where earlier studies had focused on and certain aspects untouched by them.

Reddy et al. (2018) in their study suggests that academic streams have no impact on the amount of stress. However, stress should be dealt at personal, social and institutional level. Different measures like psychotherapy, yoga, life skills training, mindfulness, meditation and feedback method have been found useful in dealing with stress. Dimitrov (2017) in his study suggests that the welfare of the students can be addressed by means of recreation, regular exercises, and food habits, which in turn helps in managing the stress. His study also reveals that the current education system places more emphasis on the academic qualifications and does not contribute enough to the holistic development of students. This competitive academic focus makes students more fearful in case of failure. Fresh graduates need more communication skills development for better placements. 
Subramani and Kadhiravan (2017) have assessed the link between academic stress and mental health among students. Their study represents good correlation between academic stress and mental health. The students faces lots of pressure from parents and school for the academic performance but they don't get equally good guidence. The students are mentally healthy when they perform constructively and consistently in the academic forums. The study also describes that there is a significant difference in mental health of students from private and government schools. He asserted that students from private schools have a different nurturing and vast exposure as compared to government school students who belong to poor socio economic background and lack of exposure. This is one of the reasons for the escalation of stress. Sharma et al. (2016) in their study have delineated various method for dealing with stress. These methods included exercise, time management, leisure activities etc. Also, the importance of conducive environment in reducing stress was stated. Change in the style of delivery from teachers end and providing mentors can also help in creating stress-free environment.

Prabu (2015in his study on higher secondary students found that male students are more stressed as compared to female students. Urban student's academic stress is greater than that of the rural students. Government school student's stress is lower as compare to the private school student's stress. Students from Science stream are more stressed than the students from Arts. Deb et al. (2014), studied on 400 male students from five private secondary schools in Kolkata who were studying in grades 10 and 12. 35 percent students were found to have high academic stress and 37 percent were found to have high anxiety levels.

Struthers et al. (2010) examined the influence of examination stress on grade and measured students' perceptions of worry. According to Denscombe (2000) it is possible to conceptualize examinations as stressful by virtue of their own properties or functions without having to refer to perceived worry and arousal. Putwain (2008) indicated how stress is also used as an umbrella term for any negative affect associated with examinations: time pressure, the exhaustion of having to sit multiple of examinations in a single day, having to prepare for exams while still completing coursework and the interference on relationships and social activities. The test anxiety construct is too narrow to capture these features of examination stress, but at the same time, owing to its lack of specificity, this broad notion of examination stress is not always helpful.

Denscombe (2012) suggested that examinations are stressful for this group of student for different reasons consequences such as markers of self-esteem, judgements from others, and fear appeals by teachers.

Intelligence is one of the most elusive concepts. Looked at in one way everyone knows what intelligence is, looked at in another way, no one does. Implicit theories of intelligence differ from explicit theories and western perspective of intelligence differ from eastern perspective. Conceptions of intelligence among different cultures also tend to differ in emphasizing different characteristics. However, a perusal of earlier and new definitions of the concept reveals that common themes running in earlier definitions of intelligence appear to be with respect to ability to adopt to the environment and ability to learn. Pahuja (2004) noted that an individual is said to be intelligent in proportion as he is successful in meeting general life situations. Analysis of modern conception of intelligence points to these interpretable factors, viz. verbal intelligence, problem solving ability and practical intelligence.

Kaur et al. (2004) found positive and significant relationship between intelligence and scientific attitude of students. High intelligent students showed less stress due to their positive attitude. If looked upon intelligence in this way, studying in terms of behaviour in the real-world environment is of great importance. Examination is one such case of real-life situation.

Behaviour of students with regard to examination cannot be taken as continuation of general behaviour in other situations. Perceptions and reactions of different students would be different in this regard. Similar would be the case as for strategies to deal with and cope with are concerned.

Saklofske et al. (2016) explored the associations amongst personality, coping, locus of control, emotional intelligence and health behavior of Canadian students. Consistent associations with health behaviors were found for conscientiousness, with the correlation pattern for other measures being more variable. Emotional intelligence, coping and health locus of control scales were inter-correlated, and a scale-level factor analysis suggested the extraction of a super ordinate coping factor. This was found to mediate the relationship between personality and both taking regular exercise and healthy diet strategy. These findings suggest that associations between coping and emotional intelligence, and the ways in which emotional intelligence can act as a coping resource, should be investigated further.

Austin et al. (2010) explored the associations among emotional intelligence, coping, personality and examination related stress in Canadian undergraduate students. Stress was measured at the start of the semester and again in the pre examination period. Higher levels of stress were associated with lower scores on emotional intelligence components, and higher scores on emotion-focused coping and neuroticism. A scale-level factor analysis of the emotional intelligence and coping subscales produced three composite factors, which each had high loadings from at least one emotional intelligence and one coping subscale. The associations of the emotion regulation factor and the task focus factor with personality, stress and subjective well-being, emotional intelligence were examined using structural equation modeling. The results showed that these factors mediated the effect of personality on stress, subjective well-being and emotional intelligence.

Personality is the whole integrated pattern of behavior which distinguished one person from another as uniquely as fingerprints and as distinctively as photographs. It consists not of incidental, emotionally neutral features but the most important things we can say about a person. Everyone has a unique personality. 
Pahuja (2004) expressed that our personality is a unique organization of so many things that belong to our self. The construct of personality may be conceived as a psychic system of structures and functions. It is not a mixture of unrelated traits and miscellaneous behaviors but a tightly knit organization of stable structures and coordinated functions. Given the continuity in one's constitutional equipment and a narrow bend of experiences for learning behavioral alternatives, this system develops an integrated pattern of characteristics and inclinations that are deeply rooted and cannot be easily eradicated, and pervade every fact of life. This system is what the term personality implies. For each of us this configuration representing an interlocking of various psychological processes would determine the disposition, i.e. how one would react to, behave and handle a given situation in normal as well as in times of crisis. Here it would reflect one's dynamic pattern of adaptive competences. It implies that the same environmental stimuli tend to evoke different reaction tendencies in people. The examination represents one such typical psychological situation, which is taken by each and every student differently in some evoking a competitive and healthy zeal, while in others, making them defensive, avoiding or frightened.

Saklofske et al. (2006) explored the associations amongst personality, coping, health locus of control, emotional intelligence and health behaviors of Canadian students. Consistent associations with health behaviors were found for conscientiousness, with the correlation pattern for other measures being more variable. Emotional intelligence, coping and health locus of control scales were inter-correlated, and a scale-level factor analysis suggested the extraction of a super ordinate coping factor. This was found to mediate the relationship between personality and both taking regular exercise and healthy diet strategy. These findings suggest that associations between coping and emotional intelligence, and the ways in which emotional intelligence can act as a coping resource, should be investigated further.

Social development is an important aspect of personality development. Chan and Zhang (2012) explored that temperament and personality have been presumed to affect achievement goals based on the hierarchical model of achievement motivation. This research investigated the relationships of temperament dimensions and the Big Five personality traits to achievement goals based on the achievement goal framework among 775 Chinese students. Six of the nine temperament dimensions i.e. activity level--general, flexibility-rigidity and task orientation significantly predicted mastery-approach, mastery-avoidance, performance-approach and performance-avoidance goals. Neuroticism, extroversion and conscientiousness significantly predicted all the above mentioned four achievement goals; openness and agreeableness significantly predicted the mastery-orientated and performance oriented achievement goals, respectively. Compared with temperament, personality was the stronger predictor for achievement goals.

Most of us develop a strong urge to assert ourselves to achieve, to get recognition in some shape or form. This has been called motive to achieve or mastery motive.
When a person expects that his performance will be evaluated in relation to some standard of excellence, such behavior is achievement-oriented. Panda and Jena (2000) defined achievement motivation as an urge to improve or as a psychological factor which provides internal impetus to excellence. Desmukh (2000) considered the positive aspect of achievement motivation as to have a sense of attainment, self-actualization or self-fulfillment.

The term achievement motivation has been defined by various psychologists as the tendency to maintain and increase the proficiency of an individual in specific area of work. It is an urge to improve. It implies dissatisfaction with the present state of affairs. Singh (2011) compared the academic achievement motivation of adolescent from aided and non-aided school. Results showed that there is significant difference in academic achievement motivation between aided and non-aided high school boys, there is significant difference in academic achievement motivation between aided and non-aided high school girls and there is no significant difference in academic achievement motivation between aided and non-aided high school pupils.

Achievement oriented person is the one who sincerely tries to improve the conditions of life for himself. Reber and Emily (2001) explained achievement motivation as a socially characterized need with two critical components, a set of internalized standards that represent personal achievement or fulfillment and a theoretical emerging or motivating condition that impels the person towards attempts to meet these standards.

\section{CONCLUSION:}

Previous studies have suggested that the degree of stress experienced by students is affected by characteristics of education, teachers and the students themselves. They remained mostly in the fields of occupational stress, stressful life events and stress due to some chronic diseases etc. But less attention has been paid to the issue of examination stress, realizing the present day need in the area of education where focus is upon mobilizing and directing the inner potentialities of students to cope with difficulties and achieve better. Based on the above gap analysis, the study of examination stress should be given the emphasis for future research, especially as it exists in relation to one's cognitive functioning.

The other variables can be focused in such studies are intelligence, personality and achievement motivation. Students react differently with the event of examination. It is yet to be explored whether more intelligent students take the examination as challenge and utilize their maximum energy to do the best. Personality has different traits and any particular trait may help the individuals to react in a specific way for the coming possibilities. Some students want to achieve the standard of excellence in every sphere of life but examination stress plays its role everywhere. It may vary with varying levels of intelligence, personality and achievement motivation. Hence the investigators have great opportunities for the research in the field of examination stress. 


\section{REFERENCES:}

[1] Acharya, Y.T. (1996) The Relationship Between Personality and Essential Hypertension. Indian Psychological Review, 46, 3-4, 50-56.

[2] Agarwal, A and Khokhar, C.P. (1999) Frustration and Anxiety in Diabetics and Normals. Praachi Journal of Psycho-Cultural Dimensions, 15, 2, 157-161.

[3] Agarwal, S.C. and Singh, S. (2004) Achievement Motivation of Co-Educational and Single Sex Educational Secondary Students. Indian Journal of Psychometry and Education,35,1, 26-31.

[4] Ahmed, Jasmine (1998) Achievement Motivation Differences Among Adolescent Boys and Girls of Various Birth Position. Indian Psychological Review, 50, 1, 70-75.

[5] Barrett, L., \& Connot, R. (1986). Knowing student personality can help school, classroom, activity participation. NASSP Bulletin, February, 39-45.

[6] Bhatia, Sanjay (1999) Stress Management in the Work Place. Praachi Journal of Psycho-Cultural Dimensions, 15, (12), 111-114.

[7] Block, J., Weiss, D.S. and Thorne, A (1979) How Relevant is a Semantic Similarity Interpretation of Personality Rating? Journal of Personality and Social Psychology. 37, (10), 55-74.

[8] Borich, G.D. and Tombari, M.L. (1997) Educational Psychology, New York: Addison - Wesley Publishers Inc.

[9] Braden, J. P. (1995). Intelligence and personality in school and educational psychology. International handbook of personality and intelligence, 621-650 New York: Plenum.

[10] Brown, D. (2000). Principles of language learning and teaching. White Plains, NY: Longman.

[11] Carskadon, T. (1978). Use of the Myers-Briggs Type Indicator in psychology courses and discussion groups. Teaching of Psychology, 5(3), 140-142.

[12] Choudhary, Nirmala (1971) The Relationship Between Achievement and Anxiety, Intelligence, Sex, Social Class and Vocational Aspirations. Unpublished Doctoral Thesis, Chandigarh: Department of Psychology, Panjab University.

[13] Choudhary, Uma (1974) Thematic Apperception Test, Indian Adaptation of Murray, H.A. (1943) Thematic Apperception Test, U.S.A.: Harvard College.

[14] Clark, M.H. and Schroth, C.A. (2010) Examining Relationships Between Academic Motivation and Personality Among College Students. Learning and Individual Differences, 20, 1, 19-24, February.

[15] Cullain (2000) The Effects of Social Stories on Anxiety Levels and Excessive Behavioral Expressions of Elementary School-aged Children with Autism. Dissertation Abstracts International, 62, (7), 2002.

[16] Das, I and Rai, S. (2004) Impact of Religious Beliefs Leisure Time Activities on Stress of Elderly. Psycho-Lingua, 34(2), 132-134.

[17] Dash, W.N., Kantha, S.K. and Dash, M. (1999) Cognitive Patterns of Good and Poor Readers Varying in Intelligence. Indian Psychological Review, 52, 53 (3-4), 109-122.

[18] Denscombe, M. (2000) Social Conditions for Stress. British Educational Research Journal, 26, 3, 259-265.

[19] Dimitrov.G (2017). A study on the impact of Academic Stress among college students in India, Ideal Research. 2(4).

[20] Prabu Suresh P (2015). A study on academic stress among higher secondary stress,

[21] International Journal of Humanities and Social Science Invention, 4(10), 63-68.

[22] Reddy,K.J., Menon. K., Anjanathattil (2018). Academic Stress and its Sources among University Students, Biomed Pharmacol Journal,11(1), 531-537.

[23] Subramani, C. and Kadhiravan, S. (2017). Academic Stress and Mental Health among High School Students, Indian Journal of Applied Research, 7(5).

[24] Sharma,B. Kumar,A. and Sarin,J. (2016). Academic Stress, Anxiety, Remedial Measures dopted and Its Satisfaction among Medical Student, A Systematic Review, International Journal of Health Sciences and Research, 6(7), 368-376 